\title{
Air-gap membrane distillation for the separation of bioethanol from algal- based fermentation broth
}

Patrick Loulergue ${ }^{1,{ }^{*}}$, Béatrice Balannec ${ }^{1}$, Lou Fouchard-Le Graët ${ }^{1}$, Audrey Cabrol $^{1}$, Walaa Sayed ${ }^{1,2,3}$, Hayet Djelal ${ }^{2}$, Abdeltif Amrane ${ }^{1}$, Anthony Szymczyk ${ }^{1}$

${ }^{1}$ Univ Rennes, École Nationale Supérieure de Chimie de Rennes, CNRS, ISCR - UMR 6226, F-35000 Rennes, France

${ }^{2}$ UniLaSalle-Ecole des Métiers de l'Environnement, Campus de Ker Lann, 35170 Bruz, France ${ }^{3}$ Université Libanaise, EDST, Centre Azm pour la Recherche en Biotechnologie et ses Applications, LBA3B, Rue El Mitein, Tripoli, Lebanon *corresponding author: patrick.loulergue.1@univ-rennes1.fr Univ. Rennes 1 - ISCR, Bat 10A, 263 Avenue du Général Leclerc, CS 74205, 35042 Rennes, France

\begin{abstract}
:
More than $80 \%$ of the energy consumed in the world comes from fossil fuels alone. However, fermentative production of bioethanol has recently gained a considerable interest as an alternative and renewable fuel. Among the different biomasses, the use of macro-algae hydrolysate as the fermentation substrate has been shown to be interesting. However, after fermentation, ethanol has to be separated from the complex broth containing numerous compounds such as microorganisms, fermentation co-products, non-fermentable organic matter, salts, etc. In this study, Air-Gap Membrane Distillation (AGMD) was evaluated to extract ethanol from these complex mixtures. Experiments were conducted using synthetic mixtures and real algal-based fermentation broths. AGMD was able to obtain an ethanol-enriched permeate while other compounds were retained by the membrane. Furthermore, by adjusting the operating parameters, it was possible to maximize the process productivity and selectivity at the same time. Finally, working with the real biofluids revealed that AGMD operation was robust toward membrane wetting, even in presence of membrane fouling. AGMD was thus demonstrated to be a suitable technique for bioethanol extraction from algal-based fermentation broths.
\end{abstract}




\section{Keywords:}

Bioethanol, macro-algae, fermentation broth separation, air-gap membrane distillation (AGMD)

\section{Highlights:}

- Bioethanol production using macro-algal hydrolysate

- Air-Gap Membrane Distillation for ethanol extraction from fermentation broths

- Simultaneous maximization of permeate flux and ethanol enrichment coefficient

- No membrane wetting despite a thick cohesive organic cake on the membrane surface

\section{Introduction}

Our society is strongly dependent on finite fossil resources to meet basic needs of energy, fuels and organic chemicals. It has thus become of key importance to find other raw materials for fuels and organic chemicals production. Therefore, new manufacturing concepts have been developed in the last decades to produce a multitude of bio-products from biomass.

Among others, fermentative production of bioethanol has recently gained a considerable interest as a clean, safe and renewable fuel. Thus, bioethanol is considered as the renewable fuel having the largest potential to replace fossil-based fuels [1]. Furthermore, bioethanol is also an interesting raw material for the chemical synthesis as a number of chemicals including ethyl acetate, butanol, acetate or hydrogen can be derived from bioethanol [1].

Among the different solutions for bioethanol production, algal-based process has emerged as a promising technique during the 2000's [2]. One major advantage of using algae as feedstock for bioethanol production is that it does not compromise food supplies and arable land. A number of algal components such as starch, cellulose or others carbohydrates produced by various types of macro- or micro-algae can be used [3].

Algae for bioethanol production can either come from artificial culture or nature stock [4]. In particular, algal biomass proliferating in coastal area, usually considered as a pollutant, can be converted into a valuable product. For example, in the Brittany region (France), where the use of nitrates and phosphates for agricultural purposes has led to important green algae proliferation, up to $98,000 \mathrm{~m}^{3}$ of green algal biomass can be harvested each year on the coastline. Previous studies have shown that this algal biomass can successfully be used as a feedstock for bioethanol production 
[5]. Bioethanol production using this carbon source first requires algae hydrolysis to release sugars, followed by a fermentation step using microorganisms such as Saccharomyces cerevisiae. However, the complex broths obtained after fermentation contain not only the molecules of interest but also numerous other compounds such as microorganisms, fermentation co-products (e.g. acetic acid, glycerol), non-fermentable organic matter, etc. Furthermore, using marine algae as raw material, the fermentation broths might also contain high amounts of salts such as sodium chloride but also sulfates coming from the sulfonated polymers contained in the cell wall $[5,6]$. In this context, separation and purification of the produced biomolecules is a technical and economical challenge.

Among the different liquid phase separation techniques, membrane processes have emerged as a major technology for process intensification in various industrial fields including biomolecule separation/purification. Membrane processes are robust, require low amounts of energy and (almost) no chemicals and are thus recognized to be compatible with a sustainable production. Beside the well-established pressure-driven processes, membrane distillation (MD) is gaining considerable interest [7-10]. It is based on the use of hydrophobic microporous membranes. A temperature difference between the two sides of the membrane is created, generating a vapor pressure difference acting as a driving force for volatile compounds transfer through the membrane while non-volatile species are retained in the concentrate side. It currently exists four major configurations of MD modules: Direct-Contact Membrane Distillation (DCMD), Air-Gap Membrane Distillation (AGMD), Vacuum Membrane Distillation (VMD) and Sweeping Gas Membrane Distillation (SGMD). These modules differ by the condensation technique used in the permeate side (fig. 1). In DCMD, the permeate side is filled with a condensing fluid (pure water/permeate) directly in contact with the membrane. Alternatively, the vaporized molecules can be condensed on a cold plate after crossing an air-gap (AGMD). In the two other configurations, the vaporized molecules are transported outside of the module by mean of a vacuum pump (VMD) or a flow of inert gas (SGMD) in order to be condensed. 
$\underset{\text { Feed }}{\uparrow} \downarrow$

DCMD

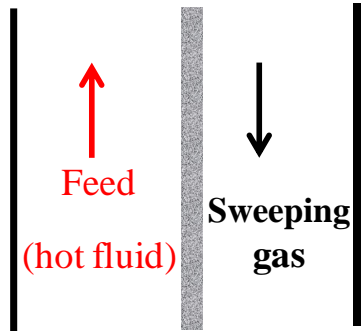

SGMD $\mid \begin{gathered}\uparrow \\ \text { Feed } \\ \text { (hot fluid) }\end{gathered}$

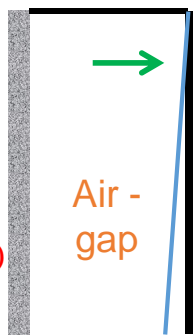

$\downarrow$

Coolant

fluid
AGMD

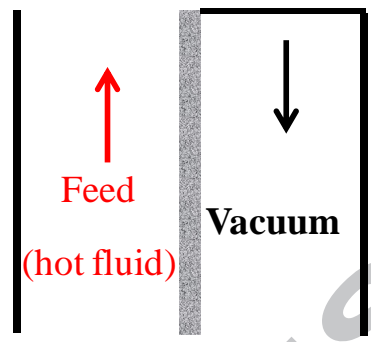

VMD

Figure 1: The 4 major configurations of MD modules (adapted from [11] with permission)

One of the main advantage of this technique is that it requires a low electric power as the temperature difference can be created through the use of low-grade energy such as waste heat $[9,11,12]$ or renewable (solar) energy [13-16]. Another main advantage of MD is that it theoretically allows a total retention of all non-volatile components (such as inorganic salts) associated with a weak impact of polarization concentration (compared to high pressure-driven membrane processes) [9]. Taking advantage of these attributes, numerous studies have been dedicated to the separation of water from salts for desalination application [12,17-20] and reverse osmosis brine concentration $[21,22]$ leading to the building of the first full scale membrane distillation unit in 2014 and the commissioning of a second plant for 2018 [23]. On the other hand, despite promising results, far less studies have been dedicated to the separation of mixtures of volatile/semi-volatile compounds (such as ethanol, acetic acid, formic acid, etc.) using MD.

Few studies dealt with the treatment of water-alcohol mixtures using MD. Among these studies, various authors applied MD to the separation of model alcohol-water binary solutions. The efficiency of the major MD module configurations have been tested including DCMD [24], VMD [25-27], SGMD [28] and AGMD [29-31]. In most reported works, a parametric study showing the influence of operating parameters is provided. For example, in the case of AGMD, Garcia-Payo et al, (2000) have applied air-gap membrane distillation to the treatment of different aqueous alcohol solutions [30]. In this study, the authors studied the influence of different operating parameters including alcohol type and concentration, air-gap thickness, feed temperature and feed flowrate. However, the alcohol concentrations in the feed solutions (from few tens to few hundreds of grams per liter) were high compared to the ethanol concentration obtained in fermentation broths $\left(<25 \mathrm{~g} \cdot \mathrm{L}^{-1}\right.$ in this study, for 
algal-based fermentation broths). In these studies, models have also been developed allowing to study heat and mass transfer, the role of concentration and thermal polarization and to predict MD performances [24,26,27]. Kujawska et al, (2016) [31] also compared AGMD to another thermally driven membrane process, namely thermopervaporation. Under the tested conditions, they concluded that AGMD was the more desirable technique to separate ethanol from water-ethanol binary mixtures (feed concentration in the range 0-4 wt \%). Unfortunately, most of these studies using synthetic mixtures focused on (over)simplistic feed solutions, like e.g. water-ethanol binary mixtures. However, one can mention the work of Banat and Simandl (1999) who evaluated the influence of $\mathrm{NaCl}$ addition (1 wt\%) on the separation of ethanol-water solution by AGMD [29]. In the tested conditions, a slight reduction of the membrane permeate flux was observed accompanied with a net improvement of the ethanol selectivity. This observation was found to be due to the reduction of water vapour pressure induced by the salt addition thus reducing the water flux. In their study, Kujawska et al, (2016) applied AGMD for the separation of model acetone-butanol-ethanol mixtures [31]. They concluded that MD is not suitable for treating such feed solution due to membrane wetting favoured by the presence of butanol. Based on these studies, and with respect to the objective to extract ethanol from complex fermentation broths, it is of key importance to study the MD performance for the separation of complex synthetic mixtures of controlled composition (including ethanol, fermentation by-products, salts, sugar...). Knowledge acquired with such experiments would further be useful to optimize the process performance when considering real biofluids.

On the other hand, several other studies have been carried out (in particular by Gryta, Tomaswewska and co-workers) to study the direct coupling of a membrane bioreactor for ethanol production and MD module for its integrated recovery [32-39]. However, most of these studies focused on bioreactor performance rather than separation performances. Thus, they highlighted the benefits of combining fermentation and MD processes. Implementation of MD allowed the continuous extraction of volatile fermentation products (such as acetic acid) which are susceptible to inhibit cell growth and ethanol productivity when accumulated in the fermentation broth. The studies carried out during more or less time (from tens to thousands of hours) generally pointed out the increase in bioreactor productivity when the fermentation is carried out together using a coupled bioreactor-MD device. Depending on the operating conditions (especially nature of the fermentation substrate, membrane properties, hydrodynamics and experiment duration), the authors pointed out the absence of membrane fouling [36] or its occurrence due to yeasts [38] or proteins [37] deposition. In an attempt to mitigate membrane fouling, Kumar et al, (2017) proposed to couple the bioreactor with a membrane cascade including microfiltration and nanofiltration prior to (solar-driven) MD [40]. 
This complex multi-steps process effectively allowed to limit membrane fouling but failed to avoid it totally as a slight permeate flux decline was observed with time (0-100 h).

Interestingly, DCMD configuration was used in all studies dedicated to the coupling of bioreactor for ethanol production and MD except for those from Calibo et al, (1989) who used SGMD and [32] Zhang et al (2017) who applied VMD to extract bioethanol from a very high gravity fermenter. From a pragmatic point of view, this is easily understandable as DCMD is the simplest configuration to design an efficient MD lab-scale set-up. However, this configuration is rarely used in (semi)industrial MD systems developed by MD manufacturers as pointed out by Thomas et al (2017) in a recent MD market survey [23]. The authors showed that, when dealing with (semi)industrial scale facilities, most installed MD systems are AGMD and that a better alignment between academic and industrial practitioners is needed regarding MD configuration choice. From an economical point of view the superiority of AGMD over DCMD was confirmed in a very recent study [41]. In an economic modelling study, Hitsov et al (2018) showed that AGMD outperform DCMD both in terms of distillate and system price at all considered scale $\left(2 \mathrm{~m}^{3} / \mathrm{d}, 10 \mathrm{~m}^{3} / \mathrm{d}, 100 \mathrm{~m}^{3} / \mathrm{d}, 1000 \mathrm{~m}^{3} / \mathrm{d}\right)$ for desalination application.

Accordingly, this study focuses on the use of AGMD to extract ethanol from algal-based fermentation broth. Firstly, synthetic feed solutions were used. Simple ethanol-water binary solutions and complex mixtures including the fermentation products (ethanol, glycerol and acetic acid), salt and sugar were considered. Using these solutions, a preliminary test was performed in order to identify the compounds able to cross the membrane. A parametric study of the performance was then conducted. Optimized operating conditions deduced from these results were further applied for the distillation of real fermentation broths. A special attention was paid to the ethanol separation performance as well as the membrane fouling.

\section{Material and methods}

\subsection{Synthetic feed solutions}

Ethanol (96\% v/v, VWR chemicals, France), glacial acetic acid (VWR chemicals, France) and glycerol (purity of $99.5 \%$ purchased from Sigma-Aldrich, Germany), sodium chloride (purity $>98 \%$, SigmaAldrich, Germany) and glucose (purity > $99.5 \%$ purity, Sigma-Aldrich, Germany) were used to prepare the synthetic solutions. All solutions were prepared using deionized water (resistivity: $18 \mathrm{M} \Omega$ $\mathrm{cm})$. 
Different synthetic feed solutions were considered: simple water-ethanol binary mixtures (Feed 1), a quaternary water-ethanol-glycerol-acetic acid mixture (Feed 2) and a complex mixture including the fermentation products but also $\mathrm{NaCl}$ and glucose (Feed 3). Their exact compositions are given in Table 1.

Table 1: composition of the different aqueous synthetic feed solutions

\begin{tabular}{cc}
\hline Feed 1 & Water-ethanol $\left(12-20-25 \mathrm{~g} . \mathrm{L}^{-1}\right)$ \\
\hline Feed 2 & Water-ethanol $\left(20 \mathrm{~g} . \mathrm{L}^{-1}\right)-$ glycerol $\left(3.0 \mathrm{~g} \cdot \mathrm{L}^{-1}\right)$ \\
& - acetic acid $\left(0.4 \mathrm{~g} . \mathrm{L}^{-1}\right)$ \\
\hline Feed 3 & Feed $2+\mathrm{NaCl}\left(14.6 \mathrm{~g} \cdot \mathrm{L}^{-1}\right)+$ glucose \\
& $\left(50 \mathrm{~g} \cdot \mathrm{L}^{-1}\right)$
\end{tabular}

The concentrations of the different species were adjusted to be representative of the broths obtained during preliminary fermentation tests carried out at lab-scale.

\subsection{Real fermentation broth}

AGMD distillation experiments were also performed using real fermentation broths from medium of hydrolysate macroalgae. $35 \mathrm{~kg}$ of hydrolysate of Chaetomorpha linum from CEVA (Pleubian-France) were used for fermentation assay with an inoculum of Saccharomyces cerevisiae CLIB 95 (CRIM, France) (0.7 mg/g hydrolysate) prepared as previously described [5]. The fermentation was conducted in a 77 liters reactor at $28^{\circ} \mathrm{C}, 250 \mathrm{rpm}$, without aeration during 48 hours. The initial pH was adjusted at 6.0 by addition of $\mathrm{KOH} 2 \mathrm{~mol} . \mathrm{L}^{-1}$.

Additional experiments were performed with fermentation broths obtained from synthetic medium model of hydrolysate of macroalgae containing glucose as the carbon source. The culture conditions of the fermentation were described in details in our previous work [5].

\subsection{Air-Gap Membrane Distillation}

\subsubsection{AGMD set-up}

A commercial membrane distillation unit (XZero AB, Sweden) was used. It consisted of a 25-litre feed tank (minimum working volume $12 \mathrm{~L}$ ) from which the fluid was pumped to a flat-sheet membrane cassette having an effective membrane area of $0.195 \mathrm{~m}^{2}$. The PTFE membranes (polypropylene 
backing) used (Gore, USA) had a pore size of $0.2 \mu \mathrm{m}$, a total thickness of $280 \mu \mathrm{m}$, a porosity of $80 \%$ and a LEP of $238 \mathrm{kPa}$ (manufacturer data). The air-gap thickness was $3.12 \mathrm{~mm}$. The same membrane module was used for all the experiments carried out with the synthetic mixtures as no membrane fouling was observed. Experiments were interspersed by pure water flux measurements to ensure the membrane integrity. Different membrane modules were used when the real biofluids were used as feed solutions.

The feed and coolant temperatures were continuously monitored both at the inlet and outlet of the membrane module. Feed and coolant temperatures were calculated as the average of the inlet and outlet temperatures on the feed and coolant sides, respectively.

Beside the feed composition, the influence of several operating parameters was evaluated including: (hot) feed temperature, feed and coolant flowrates. The feed temperature was adjusted in the range 35-55 ${ }^{\circ} \mathrm{C}$. The range of feed flowrate was from 2 to $5 \mathrm{~L}$. $\mathrm{min}^{-1}$ while it was from 4 to $10 \mathrm{~L}^{\mathrm{min}}{ }^{-1}$ for the cold fluid. Cold water from the chilled water network of the building $\left(15 \pm 1^{\circ} \mathrm{C}\right)$ was used as the coolant fluid. All experiments were performed with a total recycling of the concentrate and permeate towards the feed tank (volume reduction ratio VRR $=1$ ) to ensure a constant composition of the feed solution.

\subsubsection{Performance analyses}

In this study, AGMD separation performance was evaluated according to two key parameters: the total permeate flux (J) and the enrichment coefficient (EC).

The permeate flux is defined as follows:

$$
\left.J=\frac{\Delta m}{\Delta t * S} \quad \text { (eq. } 1\right)
$$

\section{With:}

- $\quad \Delta \mathrm{m}$ the permeate mass collected $(\mathrm{kg})$

- $\Delta \mathrm{t}$ the sampling time $(\mathrm{h})$

- $\quad$ S the effective membrane surface $\left(\mathrm{m}^{2}\right)$

The permeate was sampled every $20 \mathrm{~min}$ and then weighed with a precision scales. All measurements were performed in duplicates and an average value was calculated. The precision on the permeate flux calculation was better than $5 \%$. 
In addition to the permeate flux, the enrichment coefficient can be calculated for a given compound using equation 2. Retentate and permeate concentration were determined by High-Performance Liquid Chromatography for the different compounds (ethanol, glycerol and acetic acid).

$$
E C_{i}=\frac{C p_{i}}{C_{f i}}
$$

With:

- $\quad E C_{i}$ the enrichment coefficient of species $i$

- $C p_{i}$ the concentration of $\mathrm{i}$ in the permeate $\left(\mathrm{g} \cdot \mathrm{L}^{-1}\right)$

- $\quad C f_{i}$ the concentration of $\mathrm{i}$ in the feed $\left(\mathrm{g} \cdot \mathrm{L}^{-1}\right)$

An enrichment coefficient value equal to 1 means that the concentration in the permeate and the feed are the same and thus the membrane is not able to separate the compound from the feed solution. For a given compound, enrichment coefficient values greater than 1 indicate that the permeate is enriched compared to the feed. On the other hand, enrichment coefficient lower than 1 indicate that the compound is retained by the membrane and thus its concentration in the retentate compartment is higher than the one in the permeate.

Regarding the separation efficiency, it is thus desirable to maximize the enrichment coefficient of compounds to be extracted (products of interest, fermentation inhibitors) from the fermentation broth while minimizing the enrichment coefficient of fermentation substrate and nutrients.

\subsection{High Performance Liquid Chromatography (HPLC)}

HPLC was used to quantify the solutes concentration in feed solution, retentate and permeate samples. A HPX-87 H (300 x 7.8 mm, BIO-RAD, Hercules, CA, USA) column was used. It was maintained at $45^{\circ} \mathrm{C}$ using an oven (Cro-Cir ${ }_{\mathrm{TM}}$, Cluzeau Info-Labo, ste Foy La Grande, France) and fed using an isocratic pump (WATERS 510, Milford, MA, USA) with Sulfuric acid (0.01 N) as eluent at a flow rate of $0.7 \mathrm{~mL} \cdot \mathrm{min}^{-1}$. Detection system was composed of a refractometer (ERC 7512, Shimadzu).

\subsection{Scanning electron microscopy (SEM)}


Images of the pristine and fouled membranes were acquired using a high-resolution field-emission scanning electron microscope (SEM) type JEOL JSM-7100F. The secondary electron emission mode was used. The apparatus was equipped with an Oxford Instruments Aztec EDS system allowing the determination of the sample composition using energy dispersive X-ray spectroscopy.

\subsection{Contact angle measurements}

The contact angle measurements were performed using the sessile drop (static) method thanks to a GBX-DS apparatus allowing the deposition of a droplet of deionized water of controlled size (close to $2 \mu \mathrm{L}$ ) on the membrane surface stuck on a glass slide. The GBX-DS was equipped with a video acquisition system and the Windrop++ software allowed the determination of the contact angle value. It has to be noted that the membrane samples were dried in a desiccator under dynamic vacuum for $72 \mathrm{~h}$ before performing the measurements. Each measured contact angle was at least the average of 8 measurements.

\section{Results and discussion}

3.1 Evaluation of MD suitability for bioethanol extraction from algal based fermentation broths

Fermentation broths obtained from algal hydrolysates are complex mixtures containing ethanol but also other fermentation by-products, salts, sugars, etc. It is thus of key importance to determine, which compounds are rejected or transferred through the membrane when using AGMD.

A synthetic mixture (Feed 2 solution) containing the major fermentation products (ethanol, glycerol acetic acid) was used as the feed solution. The concentration of the different species in both the feed and permeate and their according EC are shown in figure 2.

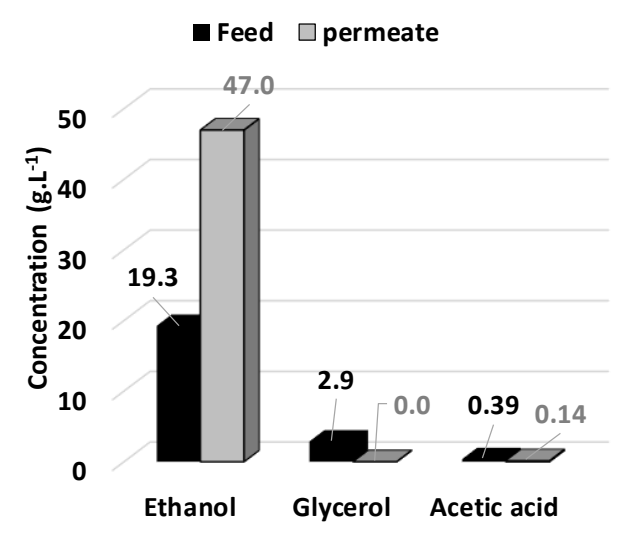

\begin{tabular}{c|c} 
& EC \\
\hline ethanol & 2.40 \\
glycerol & 0.00 \\
acetic acid & 0.36
\end{tabular}


Figure 2: Concentration of ethanol, glycerol and acetic acid in the feed and permeate solutions

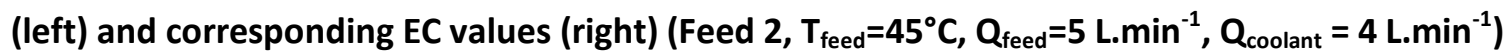

The permeate was enriched in ethanol compared to the feed solution $\left(E C_{\text {ethanol }}=2.40\right)$. This can be explained by the higher volatility of ethanol compared to water. Furthermore, acetic acid was only partly transmitted through the membrane $\left(\mathrm{EC}_{\text {acetic acid }}=0.36\right)$. The concentration of acetic acid being low in the feed solution (representative of the real fermentation broths obtained from macro-algae hydrolysates), the amount of acetic acid in the permeate was really low $\left(<0.15 \mathrm{~g} . \mathrm{L}^{-1}\right)$. As expected, due to its low volatility, glycerol was fully retained by the membrane. Furthermore, AGMD also allowed the full retention of inorganic salts (including necessary nutrients for biomass growth and ethanol production) and sugars (tested using Feed 3 solution).

These results indicate that AGMD was suitable for algal-based fermentation broth processing as it allowed the extraction of the targeted compound (ethanol) while retaining the fermentation substrate and nutrients into the broth (and thus inside the bioreactor in continuous fermentation mode).

In the tested conditions, the permeate produced is thus considered mostly as a water-ethanol mixture, the acetic acid concentration being negligible. In the following section of this paper, dedicated to the AGMD performance optimization, enrichment coefficient of acetic acid will thus not be further considered. In the same way, glycerol, which is fully retained by the membrane, will also not be considered. The parametric study performed using model solutions thus only focused on the influence of operating parameters on total permeate flux and ethanol enrichment coefficient.

\subsection{Parametric study}

In order to better understand the AGMD performance for the treatment of algal-based fermentation broths containing ethanol, a parametric study was performed. The influence of different parameters including feed composition, feed temperature $\left(\mathrm{T}_{\text {feed }}\right)$ and feed and coolant flowrates $\left(\mathrm{Q}_{\text {feed }}\right.$ and $\mathrm{Q}_{\text {coolant }}$, respectively) was studied using synthetic solutions of different complexity.

\subsubsection{Influence of feed composition and feed temperature}


The influence of ethanol concentration in water-ethanol binary mixtures was first considered at different feed temperatures. Figure 3 shows the impact of feed ethanol concentration $\left(12-25 \mathrm{~g} \cdot \mathrm{L}^{-1}\right)$ on permeate flux and enrichment coefficient for different feed temperatures in the range 35 to $55^{\circ} \mathrm{C}$.
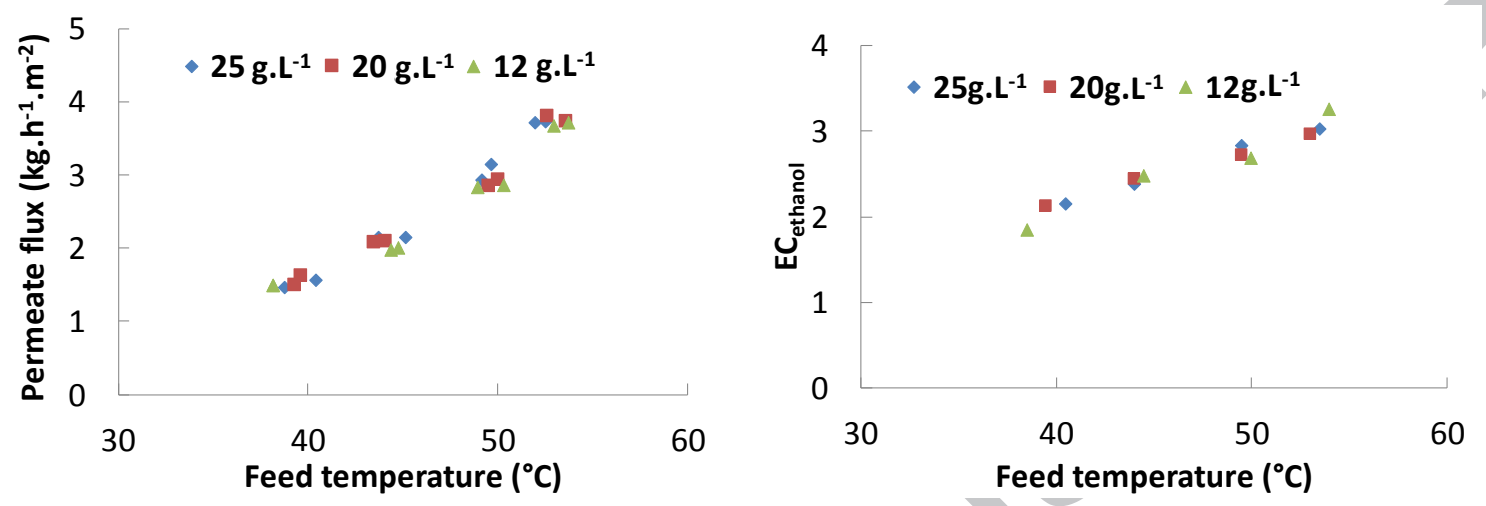

Figure 3: Influence of ethanol concentration and feed temperature on AGMD performance of

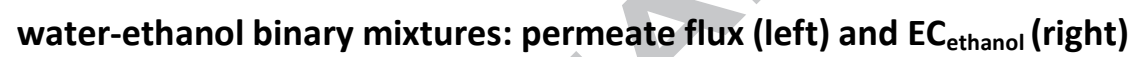

$$
\left(Q_{\text {feed }}=5 \text { L. } \min ^{-1}, Q_{\text {coolant }}=4 \text { L. } \min ^{-1}\right)
$$

As shown in previous studies $[12,18,19,42,43]$ and observed on figure 3 , feed temperature is one of the most impacting parameters on MD performance. Thus, the classically observed increase in the permeate flux with the feed temperature (at constant coolant fluid temperature) can be explained by the temperature dependence of the vapor pressure (separation driving force) according to the Antoine's law [7]. An increase of the feed temperature thus leads to an increase of the separation driving force and consequently to a higher permeate flux. $\mathrm{EC}_{\text {ethanol }}$ was also found to increase with temperature.

Regarding the ethanol concentration in the binary mixture, it was observed that it had no impact on permeate flux (Fig. 3), whatever the feed temperature. This could be explained by the rather low ethanol concentration in the feed and permeate solutions. Whatever the feed composition tested, the permeate thus mostly contained water leading the total permeate flux to be insensitive to the feed ethanol composition in the tested range. This observation is in accordance with previous work from Garcia-Payo et al, (2000) [30]. In the same way, $\mathrm{EC}_{\text {ethanol }}$ was found to be insensitive to ethanol concentration.

More interesting, in this study, it was observed that both the permeate flux and $\mathrm{EC}_{\text {ethanol }}$ increased with the feed temperature (Fig.3). Figure 4 shows a plot of $\mathrm{EC}_{\text {ethanol }}$ against the permeate flux for the 
water-ethanol binary mixtures. In the tested conditions, $\mathrm{EC}_{\text {ethanol }}$ increased with the permeate flux and a maximum value of $\mathrm{EC}_{\text {ethanol }}$ of 3 can be reached for a permeate flux close to $4.0 \mathrm{~kg} \cdot \mathrm{h}^{-1} \cdot \mathrm{m}^{-2}$.

This finding indicates that both the permeate flux and $\mathrm{CE}_{\text {ethanol }}$ can be maximized simultaneously. From a process point of view this a very interesting outcome as it means that no compromise has to be found between maximizing the permeate flux and the permeate enrichment in ethanol. In other words, both the productivity and the selectivity can be maximized at the same time.

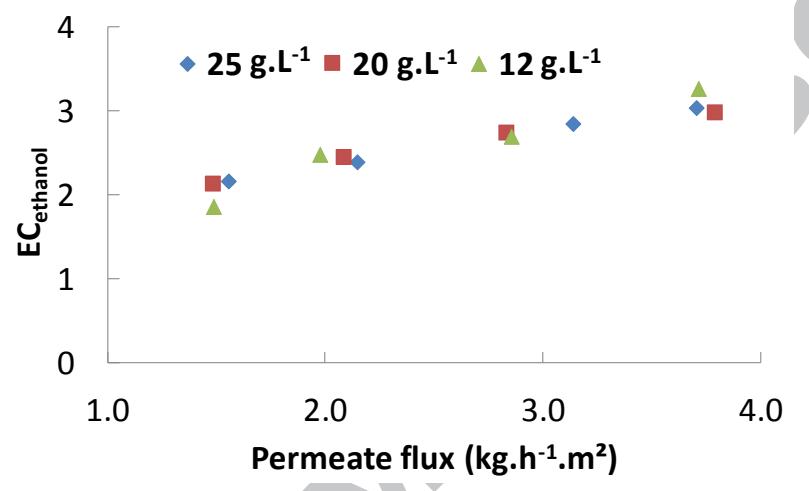

Figure 4: variation of $\mathrm{EC}_{\text {ethanol }}$ according to permeate flux for the water-ethanol binary mixtures

$$
\left(T_{\text {feed }}=38-55^{\circ} \mathrm{C}, Q_{\text {feed }}=5 \mathrm{~L} \cdot \mathrm{min}^{-1}, Q_{\text {coolant }}=4 \mathrm{~L} \cdot \mathrm{min}^{-1}\right)
$$

In order to gain insight into the influence of the feed solution chemistry on AGMD of complex mixtures, model solutions containing ethanol, glycerol and acetic acid, with or without sodium chloride and glucose, have also been considered. Sodium chloride was added to the feed solution at a concentration of about $15 \mathrm{~g} . \mathrm{L}^{-1}$ representative of the concentration observed in the marine algae hydrolysate. Glucose was selected as a model of sugars present in the algal hydrolysate. Figure 5 shows the variation of the permeate flux and $\mathrm{EC}_{\text {ethanol }}$ for the different feed solutions.
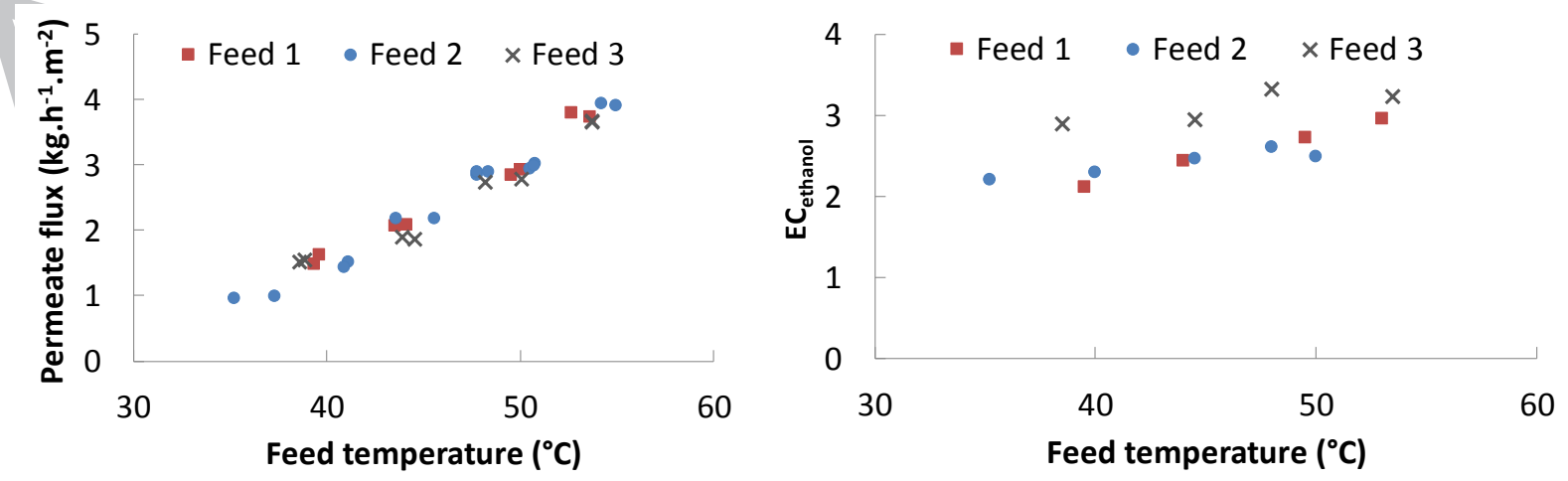
Figure 5: Influence of synthetic mixtures composition on AGMD performance: permeate flux (left) and $\mathrm{EC}_{\text {ethanol }}\left(\right.$ right) (Feed 1: water-ethanol mixture $\left(20\right.$ g. $\left.\mathrm{L}^{-1}\right)$; Feed 2: Feed $1+$ glycerol $\left(3 \mathrm{~g} . \mathrm{L}^{-1}\right)+\operatorname{acetic}$ acid $\left(0.4 \mathrm{~g} . \mathrm{L}^{-1}\right) ;$ Feed 3: Feed $2+$ Glucose $\left(50 \mathrm{~g} \cdot \mathrm{L}^{-1}\right)+\mathrm{NaCl}\left(15 \mathrm{~g} \cdot \mathrm{L}^{-1}\right) ; \mathrm{Q}_{\mathrm{feed}}=5 \mathrm{~L} . \mathrm{min}^{-1}$ ， $Q_{\text {coolant }}=4$ L. $\mathrm{min}^{-1}$ )

As previously observed for the simple water-ethanol binary mixtures, the permeate flux was independent of the feed composition. However, the picture was different regarding $\mathrm{EC}_{\text {ethanol }}$. Thus, in the tested conditions, glycerol and acetic acid addition to the water-ethanol mixture did not seem to have an impact on $\mathrm{EC}_{\text {ethanol. }}$. However, the addition of sodium chloride and glucose led to an increase of $E C_{\text {ethanol. }}$ This could be explained by the existence of salting-out and/or sugaring-out effects [4446]. Briefly, the addition of salt or sugar to water-alcohol mixtures can change both the water and ethanol volatility due to molecular interactions between the different species. Indeed, it has previously been demonstrated that salt (or sugar) presence might facilitate water-alcohol separation $[45,46]$. This finding underlines the necessity to take into account the physico-chemical interactions occurring between the feed components to predict MD separation performance more accurately.

As previously observed for the binary mixtures, an increase of both $\mathrm{EC}_{\text {ethanol }}$ and the permeate flux with the feed temperature occurred for these more complex mixtures (figure 5).

\subsubsection{Influence of feed and coolant flowrates}

The influence of both the feed and coolant flowrates were studied (fig. 6). For this set of experiments, the feed and coolant temperatures were maintained at constant values $0 f 50^{\circ} \mathrm{C}$ and $15^{\circ} \mathrm{C}$ respectively. The feed solution used was the complex mixture including ethanol, glycerol and acetic acid (Feed 2).
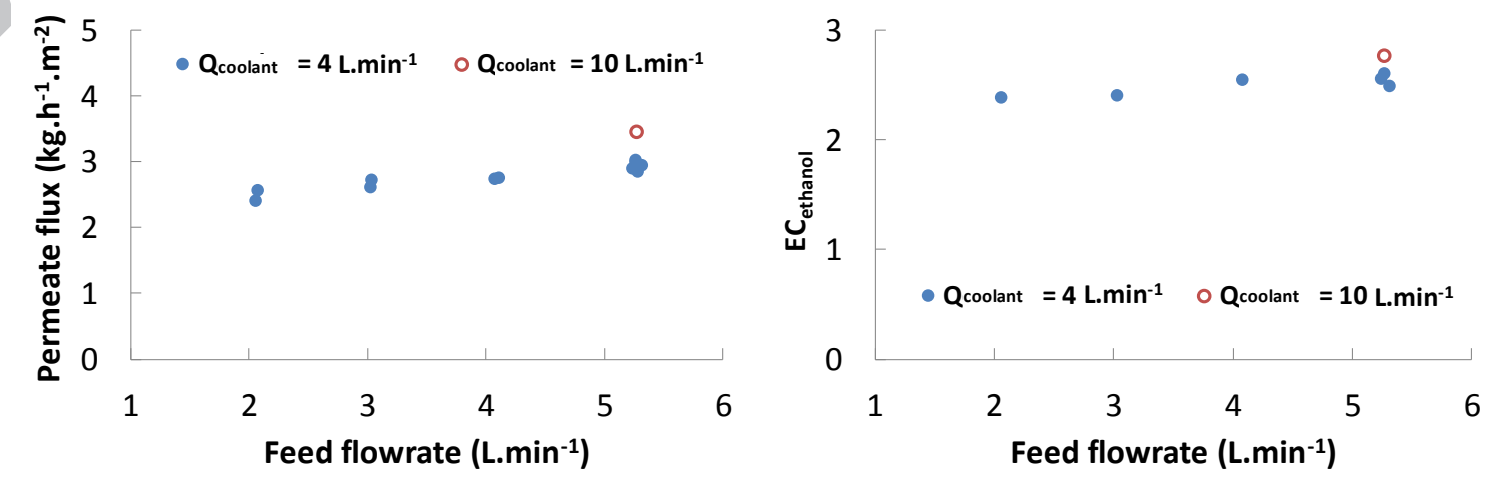
Figure 6: Influence of feed and coolant flowrates on AGMD performance: permeate flux (left) and

$$
\mathrm{EC}_{\text {ethanol }} \text { (right) (Feed 2, } \mathrm{T}_{\text {feed }}=50^{\circ} \mathrm{C} \text { ) }
$$

For a coolant flowrate of $4 \mathrm{~L} \cdot \mathrm{min}^{-1}$, a slight increase of both the permeate flux and $\mathrm{EC}_{\text {ethanol }}$ with the feed flowrate was observed. Thus, when the feed flowrate was increased from 2 to 5.5 L. $\mathrm{min}^{-1}$, a permeate flux increase of roughly $20 \%$ occurred (from $2.5 \mathrm{~kg} \cdot \mathrm{h}^{-1} \cdot \mathrm{m}^{-2}$ to $3.0 \mathrm{~kg} \cdot \mathrm{h}^{-1} \cdot \mathrm{m}^{-2}$ ). This could be explained by the increase of the Reynolds number (due to the increased velocity) with the feed flowrate, which led to a reduction of the boundary layer thickness (and accordingly of thermal and concentration polarization) and thus an increase of the fluid temperature at the membrane surface. However, the impact on $\mathrm{EC}_{\text {ethanol }}$ was less pronounced as the increase was only of about $8 \%$ (from 2.4 to 2.6$)$.

Furthermore, increasing the coolant fluid flowrate from 4 to $10 \mathrm{~L} \cdot \mathrm{min}^{-1}$ (at a constant feed flowrate of $5.5 \mathrm{~L} \cdot \mathrm{min}^{-1}$ ) had also a slightly positive effect on both the permeate flux and $\mathrm{EC}_{\text {ethanol }}$ as they increased by $13 \%$ and $8 \%$, respectively. This could be explained by the increase of the Reynold number (due to increased velocity in the cooling channel) thus increasing the convective heat transfer coefficient leading to an increase in the heat transfer efficiency in the cold channel.

In the tested operating conditions, an increase of feed and/or coolant flowrates thus led to an increase in ethanol separation performance.

\subsection{AGMD study of the real fermentation-broth}

In this section, the results obtained for the separation of the real algal-based fermentation broth (ethanol concentration: 7.4 g. $\mathrm{L}^{-1}$ ) are presented.

According to the results obtained with the synthetic fluids, the feed fluid temperature was set to $53^{\circ} \mathrm{C}$. Due to the high viscosity of the feed solution, it was not possible to get a feed flowrate of $5 \mathrm{~L} \cdot \mathrm{min}^{-1}$. It was thus adjusted to $4.5 \mathrm{~L} \cdot \mathrm{min}^{-1}$ and the experiment was carried out for about 5 hours. The permeate was continuously recycled to the feed tank in order to maintain constant the feed composition.

\subsubsection{Process performance and membrane fouling/wetting}

Figure 7 shows the evolution of the permeate flux and $\mathrm{EC}_{\text {ethanol }}$ over time. 


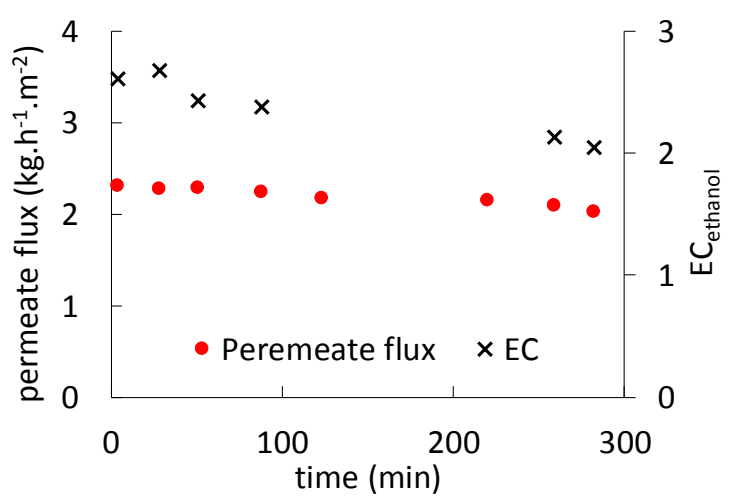

Figure 7: Time variation of the permeate flux and $\mathrm{EC}_{\text {ethanol }}$ (real algal-based fermentation broth,

$$
T_{\text {feed }}=53^{\circ} \mathrm{C}, Q_{\text {feed }}=4.5 \text { L. } \mathrm{min}^{-1}, Q_{\text {coolant }}=4 \text { L. } \mathrm{min}^{-1} \text { ) }
$$

A limited but progressive decrease of the permeate flux value was observed during the course of the experiment (from $2.3 \mathrm{~kg} \cdot \mathrm{h}^{-1} \cdot \mathrm{m}^{-2}$ to $2.0 \mathrm{~kg} \cdot \mathrm{h}^{-1} \cdot \mathrm{m}^{-2}$ ). The observed decrease of the permeate flux over time is the typical signature of membrane fouling. That is to say, performance degradation due to rejected matter accumulation at membrane surface or within its pores. Basically, membrane fouling in $\mathrm{MD}$ is a complex phenomenon involving a wide range of potential foulants including organic, inorganic and biological species. Beside the fluid composition, a number of other parameters may influence membrane fouling such as: membrane material and properties, feed temperature, feed chemistry ( $\mathrm{pH}$, ionic strength, presence of divalent cations) etc. [10,47].

To confirm the occurrence of membrane fouling, the membrane module was autopsied after use. Before discharging the membrane from the set-up, a rinsing step was performed. Distilled water $(9 \mathrm{x}$ $12 \mathrm{~L}$ ) was circulated inside the membrane cassette without applying any temperature difference between the feed and permeate side (i.e. no permeate flux). Rinsing efficiency was estimated visually by checking the water color after circulation. Thus, as feed solution was dark green, rinsing step was stopped when the rinsing water remained colorless at membrane module exit.

SEM analysis of the autopsied membrane was performed and revealed that the fibrous structure of the pristine membrane (figure 8a) was not visible anymore. Instead, a dense cake layer was observed on membrane surface (figure $8 \mathrm{~b}$ and $8 \mathrm{c}$ ). The thickness of this cake layer was estimated to be a few tens of micrometers (figure $8 \mathrm{~d}$ ). 

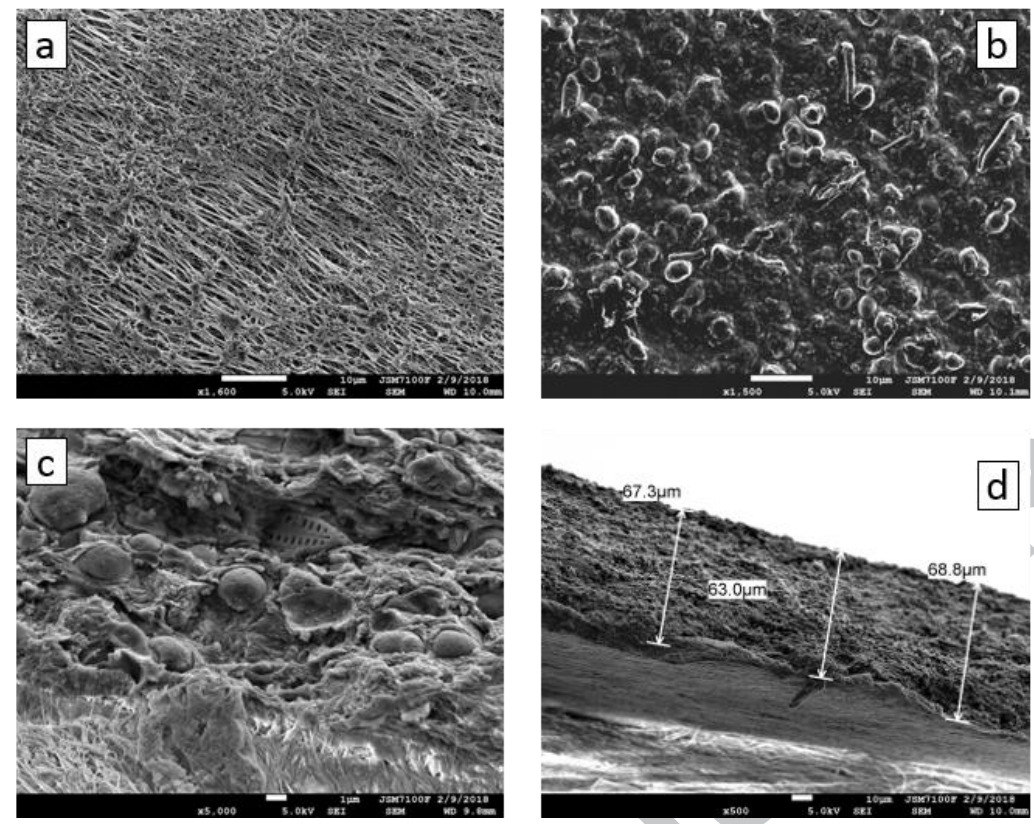

Figure 8: SEM image of the (a) pristine membrane surface $(x 1600)(b-c)$ fouled membrane surface (x1500 and x5000, respectively) and (d) fouled membrane cross-section (x500)

The formation of this cake layer could be due to the accumulation on membrane surface of particulate or colloidal matter present in the algal-based fermentation substrate. Furthermore, sieving of smaller compounds (soluble compounds) by the cake was also likely to occur $[48,49]$. Visually, it can be observed that the cake contains yeasts (globular particles visible on figure $8 \mathrm{~b}$ and c) but also many other compounds including particulate foulant such as diatoms (which were visible in figure $8 \mathrm{~b}$ and $8 \mathrm{c}$ ).

In order to get more information about the cake composition, EDS analysis was performed. Three different locations (of roughly $120 \mu \mathrm{m} \times 100 \mu \mathrm{m}$ ) were randomly selected and analyzed. The list of compounds identified and their relative amount are given in Table 2 . The cake mostly contained carbon and oxygen, which is the signature of an organic fouling layer. Furthermore, sulfur appeared to be the third more abundant element in the cake layer. This finding is not surprising as sulfate is a major component of the macro-algal cell wall $[5,6]$ and because proteins (which contains sulfur) enter in the yeast cell composition. The source of silicon was most probably the diatoms observed in fig. 8. A small quantity of calcium was also detected. It has to be noted that this is one of the most often found foulant in MD as it can easily precipitate to form calcium carbonate or calcium sulphate crystals. Furthermore, $\mathrm{Ca}^{2+}$ ions (and to a lesser extent $\mathrm{Mg}^{2+}$ ) have the ability to complex the 
negatively charged organic macromolecules, thus acting as a binding agent promoting particulate precipitation $[10,47]$.

Table 2: elemental composition of the foulant cake determined by EDS

\begin{tabular}{|c|c|c|}
\hline Element & $\begin{array}{l}\text { Mean weight } \\
\text { percentage } \\
(\% w)\end{array}$ & $\begin{array}{c}\text { Maximum } \\
\text { deviation to the } \\
\text { mean value } \\
(\% w)\end{array}$ \\
\hline C & 48.50 & 0.85 \\
\hline 0 & 43.10 & 0.28 \\
\hline$S$ & 4.32 & 0.65 \\
\hline $\mathrm{Ca}$ & 1.98 & 0.17 \\
\hline Si & 0.85 & 0.04 \\
\hline K & 0.63 & 0.07 \\
\hline $\mathrm{Mg}$ & 0.38 & 0.02 \\
\hline $\mathrm{Na}$ & 0.24 & 0.24 \\
\hline
\end{tabular}

To sum-up, a thick cohesive (i.e. not removable by a simple rinsing) organic cake was formed during the process operation leading to a decrease of the membrane separation performance. Thus, fouling layer formation in membrane processes is known to induce an additional hydraulic resistance reducing the permeate mass transfer rate. Furthermore, in MD, fouling might also be responsible for an increase in temperature polarization or a reduction in the temperature difference across the membrane thus leading to a reduced effective driving force.

On the other hand, it is well known that membrane fouling in MD might lead to wetting of the hydrophobic membrane, i.e. leakage of liquid through the membrane [50]. To evaluate the occurrence of membrane wetting, both the membrane physicochemical properties (contact angle value) and a process global operating parameter (permeate salinity) were studied. 
The fouled membranes were characterized in terms of contact angle measurements of both the feed and permeate sides of the membrane. The obtained values were compared to the ones of the pristine membranes (Table 3).

Table 3: Contact angle values of the feed and permeate sides of the pristine and fouled membranes

\begin{tabular}{lcc}
\hline & \multicolumn{2}{c}{ Contact angle value $\left(^{\circ}\right.$ ) } \\
& Active layer & Support layer \\
\hline pristine & $131 \pm 3$ & $115 \pm 4$ \\
\hline fouled & $80 \pm 9$ & $115 \pm 7$
\end{tabular}

Before use, the pristine membrane was highly hydrophobic leading to contact angle values of $131 \pm 3^{\circ}$ and $115 \pm 4^{\circ}$ for the active and support layers, respectively. After operation, the contact angle value of the active layer dramatically decreased to reach a value of $80 \pm 9^{\circ}$ indicating the rather hydrophilic character of the fouling layer. Hydrophilic nature of the (fouled) membrane surface is usually associated with a high risk of membrane wetting. However, it is interesting to note that the contact angle value of the support layer was not modified during the MD operation. This observation suggested that no liquid was able to cross the membrane and thus that no membrane wetting occurred.

To further evaluate the possible occurrence of membrane wetting, permeate conductivity was monitored and compared to the feed one. Thus, when salts are present in solution, wetting typically leads to an increase in permeate conductivity due to salt passage through the membrane. In the present case, permeate conductivity was constant in the range 30-40 $\mu{\mathrm{S} . \mathrm{cm}^{-1}}$ (while feed conductivity is $211.10^{3} \mu \mathrm{S} . \mathrm{cm}^{-1}$, i.e. salt rejection $\left.>99.80 \%\right)$. This value was comparable to that obtained when treating the synthetic fermentation broth (section 3.1). It can thus be concluded that no membrane wetting occurred despite the strong membrane fouling.

Looking at figure 7 it can be observed that $\mathrm{EC}_{\text {ethanol }}$ decreased during the course of the experiment. As no membrane wetting was observed (which would cause a leakage of the feed solution through the membrane and thus an $\mathrm{EC}_{\text {ethanol }}$ value tending toward 1), this behavior was likely the consequence of the modification of local properties at the feed/membrane interface. Thus, as explained before, membrane fouling is prone to decrease the process driving force (due to temperature polarization effect). A more precise characterization of the temperature polarization effect could be performed by using tools allowing the in-situ characterization of the temperature fields in the membrane 
module [43] or by a theoretical approach [51] (requiring the use of Computational Fluid Dynamics (CFD) due to the highly complex geometry of the membrane module used). These aspects were thus out of the scope of this study.

Change in local rheology due to foulant accumulation at membrane surface and different solute-cake interactions were likely to occur as well.

\subsubsection{Membrane distillation of a particle-free fermentation broth}

It has been shown in the previous section that the distillation of the algal-based fermentation broth containing particulate material such as yeasts, algal debris or diatoms led to the formation of a dense cake layer.

In order to gain insight into membrane fouling understanding, especially by particulate foulant, complementary experiments were performed using particle-free (pre-treated) fermentation broths. To avoid the presence of particulate material coming from the medium of hydrolysate macroalgae, fermentation was performed using a (particle-free) synthetic medium (model of hydrolysate of macroalgae). Furthermore, this fermentation broth was centrifuged before being treated by AGMD in order to remove the yeasts and other potential particulate material that could appear during the fermentation process. Thus, if carried out in proper conditions (4000 g, $10 \mathrm{~min}$ ), centrifugation is able to remove particulate matter from biological fluids while colloids and dissolved species remain in the liquid phase [52]. The centrifuged fluid, cleared of particulate matter and having an ethanol concentration of $7.0 \mathrm{~g} . \mathrm{L}^{-1}$ and a glycerol concentration of $0.35 \mathrm{~g} . \mathrm{L}^{-1}$, was then treated by AGMD. In the present fermentation conditions, glycerol is excreted as a response to the osmotic stress due the presence of salt in the marine algal hydrolysate [5].

The feed fluid temperature and flowrate were set to $53^{\circ} \mathrm{C}$ and $5 \mathrm{~L} \cdot \mathrm{min}^{-1}$ respectively. The cold fluid flowrate was adjusted to $4 \mathrm{~L}$. $\mathrm{min}^{-1}$. The experiment was carried out for about 5 hours. Permeate was continuously recycled to the feed tank in order to maintain constant feed composition.

Figure 9 shows the temporal variation of both the permeate flux and $\mathrm{EC}_{\text {ethanol }}$ during the experiments. Interestingly, no permeate flux nor $\mathrm{EC}_{\text {ethanol }}$ decline were observed. This result thus suggests that, in absence of particulate matter in the feed solution, membrane fouling is less likely to occur during MD of algal-based fermentation broths (in the tested conditions). In this study, for practical reason, it was decided to use centrifugation to obtain a fermentation broth cleared of all particulate matter. However, at larger scale, other pre-treatment techniques could be used. In particular, the use of 
micro- and ultra-filtration, that are known to be more competitive than centrifugation both in terms of capital and operating costs, should be considered.

Surprisingly, a high $\mathrm{EC}_{\text {ethanol }}$ coefficient around 4 was obtained (i.e. higher than the range of those for the synthetic mixtures and the algal based fermentation broth). Finally, full retention of the glycerol was obtained during the course of the experiment as already observed for the synthetic mixtures.

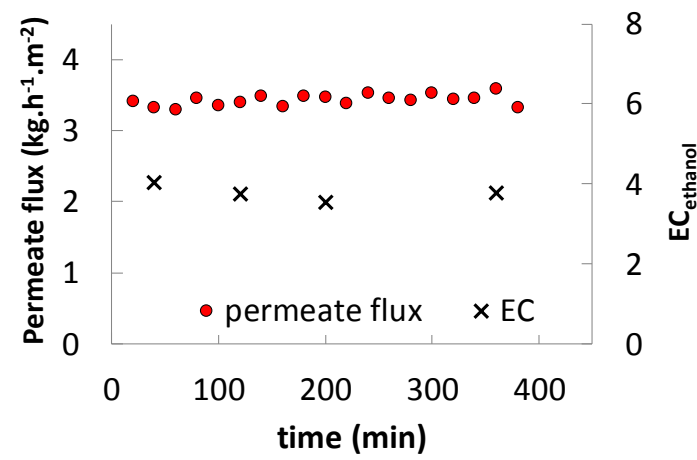

Figure 9: Time variation of the permeate flux and $\mathrm{EC}_{\text {ethanol }}$ (centrifugated fermentation broth obtained from synthetic medium, $T_{\text {feed }}=52^{\circ} \mathrm{C}, Q_{\text {feed }}=5 \mathrm{~L} \cdot \mathrm{min}^{-1}, Q_{\text {coolant }}=4 \mathrm{~L} \cdot \mathrm{min}^{-1}$ )

\section{Conclusion}

AGMD was evaluated for ethanol extraction from algal-based fermentation broths. A particularity of these fermentation broths was that, beside microorganisms, bioproducts, non-fermentable organic, nutrients etc., they also contained a high amount of dissolved salts (sodium chloride and sulfates). Experiments were carried out both using synthetic mixtures and real broths. AGMD allowed to successfully concentrate ethanol in the permeate while total retention of glycerol, sugar and salts was observed. In the tested conditions, only partial retention of acetic acid was achieved. However, due to the low concentration of acetic acid in the feed solution, its concentration was extremely low in the permeate $\left(<0.15 \mathrm{~g} \cdot \mathrm{L}^{-1}\right)$. AGMD of the algal-based fermentation broths thus allowed to obtain a permeate phase containing water and ethanol but cleared of others compounds. This could not have been achieved by classical membrane filtration techniques (such has microfiltration, ultrafiltration or nanofiltration). Furthermore, it was shown that a proper choice of operating parameters allows to 
simultaneously maximize the process productivity and selectivity. It was also observed that AGMD was robust towards membrane wetting despite heavy membrane fouling. Gathering all these results, this study underlines that MD is an efficient separation technique for ethanol extraction from algalbased fermentation broth. Further purification of the MD permeate is nevertheless required to obtain a high concentration ethanol solution and this could be achieved using pervaporation for instance.

\section{Acknowledgments :}

Francis Gouttefangeas is acknowledged for SEM images and EDS analyses performed at CMEBA (ScanMAT, University of Rennes 1) which received a financial support from the European Union (CPER-FEDER 2007-2014). The authors are grateful to the the National Agency for Research for its financial support through the project ANR Energie 2014 - GreenAlgOhol). The CEVA is acknowledged for the macro-algal hydrolysate.

\section{References}

[1] J. Baeyens, Q. Kang, L. Appels, R. Dewil, Y. Lv, T. Tan, Challenges and opportunities in improving the production of bio-ethanol, Prog. Energy Combust. Sci. 47 (2015) 60-88. doi:10.1016/j.pecs.2014.10.003.

[2] K. Dutta, A. Daverey, J.-G. Lin, Evolution retrospective for alternative fuels: First to fourth generation, Renew. Energy. 69 (2014) 114-122. doi:10.1016/j.renene.2014.02.044.

[3] R.P. John, G.S. Anisha, K.M. Nampoothiri, A. Pandey, Micro and macroalgal biomass: A renewable source for bioethanol, Bioresour. Technol. 102 (2011) 186-193. doi:10.1016/j.biortech.2010.06.139.

[4] K. Li, S. Liu, X. Liu, An overview of algae bioethanol production, Int. J. Energy Res. 38 (2014) 965-977. doi:10.1002/er.3164.

[5] W. Sayed, A. Cabrol, R. Abdallah, S. Taha, A. Amrane, H. Djelal, Enhancement of ethanol production from synthetic medium model of hydrolysate of macroalgae, Renew. Energy. (2017). doi:10.1016/j.renene.2017.10.094.

[6] A. Holzinger, K. Herburger, F. Kaplan, L.A. Lewis, Desiccation tolerance in the chlorophyte green alga Ulva compressa: does cell wall architecture contribute to ecological success?, Planta. 242 (2015) 477-492. doi:10.1007/s00425-015-2292-6.

[7] A. Alkhudhiri, N. Darwish, N. Hilal, Membrane distillation: A comprehensive review, Desalination. 287 (2012) 2-18. doi:10.1016/j.desal.2011.08.027.

[8] L.M. Camacho, L. Dumée, J. Zhang, J. Li, M. Duke, J. Gomez, S. Gray, Advances in Membrane Distillation for Water Desalination and Purification Applications, Water. 5 (2013) 94-196. doi:10.3390/w5010094.

[9] E. Drioli, A. Ali, F. Macedonio, Membrane distillation: Recent developments and perspectives, Desalination. 356 (2015) 56-84. doi:10.1016/j.desal.2014.10.028. 
[10] L.D. Tijing, Y.C. Woo, J.-S. Choi, S. Lee, S.-H. Kim, H.K. Shon, Fouling and its control in membrane distillation-A review, J. Membr. Sci. 475 (2015) 215-244. doi:10.1016/j.memsci.2014.09.042.

[11] P. Byrne, L. Fournaison, A. Delahaye, Y. Ait Oumeziane, L. Serres, P. Loulergue, A. Szymczyk, D. Mugnier, J.-L. Malaval, R. Bourdais, H. Gueguen, O. Sow, J. Orfi, T. Mare, A review on the coupling of cooling, desalination and solar photovoltaic systems, Renew. Sustain. Energy Rev. 47 (2015) 703-717. doi:10.1016/j.rser.2015.03.083.

[12] A.T. Diaby, P. Byrne, P. Loulergue, B. Balannec, A. Szymczyk, T. Maré, O. Sow, Design study of the coupling of an air gap membrane distillation unit to an air conditioner, Desalination. 420 (2017) 308-317. doi:10.1016/j.desal.2017.08.001.

[13] J. Blanco Gálvez, L. García-Rodríguez, I. Martín-Mateos, Seawater desalination by an innovative solar-powered membrane distillation system: the MEDESOL project, Desalination. 246 (2009) 567-576. doi:10.1016/j.desal.2008.12.005.

[14] J.-P. Mericq, S. Laborie, C. Cabassud, Evaluation of systems coupling vacuum membrane distillation and solar energy for seawater desalination, Chem. Eng. J. 166 (2011) 596-606. doi:10.1016/j.cej.2010.11.030.

[15] D. González, J. Amigo, F. Suárez, Membrane distillation: Perspectives for sustainable and improved desalination, Renew. Sustain. Energy Rev. 80 (2017) 238-259. doi:10.1016/j.rser.2017.05.078.

[16] A. Ali, R.A. Tufa, F. Macedonio, E. Curcio, E. Drioli, Membrane technology in renewable-energydriven desalination, Renew. Sustain. Energy Rev. 81 (2018) 1-21. doi:10.1016/j.rser.2017.07.047.

[17] A. Larbot, L. Gazagnes, S. Krajewski, M. Bukowska, Wojciech Kujawski, Water desalination using ceramic membrane distillation, Desalination. 168 (2004) 367-372. doi:10.1016/j.desal.2004.07.021.

[18] S. Cerneaux, I. Strużyńska, W.M. Kujawski, M. Persin, A. Larbot, Comparison of various membrane distillation methods for desalination using hydrophobic ceramic membranes, J. Membr. Sci. 337 (2009) 55-60. doi:10.1016/j.memsci.2009.03.025.

[19] D. Wirth, C. Cabassud, Water desalination using membrane distillation: comparison between inside/out and outside/in permeation, Desalination. 147 (2002) 139-145. doi:10.1016/S00119164(02)00601-X.

[20] A.M. Alklaibi, N. Lior, Membrane-distillation desalination: Status and potential, Desalination. 171 (2005) 111-131. doi:10.1016/j.desal.2004.03.024.

[21] R.A. Tufa, E. Curcio, E. Brauns, W. van Baak, E. Fontananova, G. Di Profio, Membrane Distillation and Reverse Electrodialysis for Near-Zero Liquid Discharge and low energy seawater desalination, J. Membr. Sci. 496 (2015) 325-333. doi:10.1016/j.memsci.2015.09.008.

[22] J.-P. Mericq, S. Laborie, C. Cabassud, Vacuum membrane distillation for an integrated seawater desalination process, Desalination Water Treat. 9 (2009) 287-296. doi:10.5004/dwt.2009.862.

[23] N. Thomas, M.O. Mavukkandy, S. Loutatidou, H.A. Arafat, Membrane distillation research \& implementation: Lessons from the past five decades, Sep. Purif. Technol. 189 (2017) 108-127. doi:10.1016/j.seppur.2017.07.069.

[24] Y. Fujii, S. Kigoshi, H. Iwatani, M. Aoyama, Selectivity and characteristics of direct contact membrane distillation type experiment. I. Permeability and selectivity through dried hydrophobic fine porous membranes, J. Membr. Sci. 72 (1992) 53-72. doi:10.1016/03767388(92)80056-P.

[25] E. Hoffmann, D.M. Pfenning, E. Philippsen, P. Schwahn, M. Sieber, R. Wehn, D. Woermann, G. Wiedner, Evaporation of alcohol/water mixtures through hydrophobic porous membranes, J. Membr. Sci. 34 (1987) 199-206. doi:10.1016/S0376-7388(00)80032-0.

[26] G.C. Sarti, C. Gostoli, S. Bandini, Extraction of organic components from aqueous streams by vacuum membrane distillation, J. Membr. Sci. 80 (1993) 21-33. doi:10.1016/03767388(93)85129-K. 
[27] M.A. Izquierdo-Gil, G. Jonsson, Factors affecting flux and ethanol separation performance in vacuum membrane distillation (VMD), J. Membr. Sci. 214 (2003) 113-130. doi:10.1016/S03767388(02)00540-9.

[28] M.M.A. Shirazi, A. Kargari, M. Tabatabaei, Sweeping Gas Membrane Distillation (SGMD) as an Alternative for Integration of Bioethanol Processing: Study on a Commercial Membrane and Operating Parameters, Chem. Eng. Commun. 202 (2015) 457-466. doi:10.1080/00986445.2013.848805.

[29] F.A. Banat, J. Simandl, Membrane distillation for dilute ethanol: Separation from aqueous streams, J. Membr. Sci. 163 (1999) 333-348. doi:10.1016/S0376-7388(99)00178-7.

[30] M.C. García-Payo, M.A. Izquierdo-Gil, C. Fernández-Pineda, Air gap membrane distillation of aqueous alcohol solutions, J. Membr. Sci. 169 (2000) 61-80. doi:10.1016/S03767388(99)00326-9.

[31] A. Kujawska, J.K. Kujawski, M. Bryjak, M. Cichosz, W. Kujawski, Removal of volatile organic compounds from aqueous solutions applying thermally driven membrane processes. 2. Air gap membrane distillation, J. Membr. Sci. 499 (2016) 245-256. doi:10.1016/j.memsci.2015.10.047.

[32] R.L. Calibo, M. Matsumura, H. Kataoka, Continuous ethanol fermentation of concentrated sugar solutions coupled with membrane distillation using a PTFE module, J. Ferment. Bioeng. 67 (1989) 40-45. doi:10.1016/0922-338X(89)90084-6.

[33] H. Udriot, S. Ampuero, I.W. Marison, U. von Stockar, Extractive fermentation of ethanol using membrane distillation, Biotechnol. Lett. 11 (1989) 509-514. doi:10.1007/BF01026651.

[34] M. Gryta, A.W. Morawski, M. Tomaszewska, Ethanol production in membrane distillation bioreactor, Catal. Today. 56 (2000) 159-165. doi:10.1016/S0920-5861(99)00272-2.

[35] G. Lewandowicz, W. Białas, B. Marczewski, D. Szymanowska, Application of membrane distillation for ethanol recovery during fuel ethanol production, J. Membr. Sci. 375 (2011) 212219. doi:10.1016/j.memsci.2011.03.045.

[36] M. Barancewicz, M. Gryta, Ethanol production in a bioreactor with an integrated membrane distillation module, Chem. Pap. 66 (2011) 85-91. doi:10.2478/s11696-011-0088-0.

[37] M. Tomaszewska, L. Białończyk, Production of ethanol from lactose in a bioreactor integrated with membrane distillation, Desalination. 323 (2013) 114-119. doi:10.1016/j.desal.2013.01.026.

[38] M. Tomaszewska, L. Białończyk, Ethanol production from whey in a bioreactor coupled with direct contact membrane distillation, Catal. Today. 268 (2016) 156-163. doi:10.1016/j.cattod.2016.01.059.

[39] Q. Zhang, Nurhayati, C.-L. Cheng, Y.-C. Lo, D. Nagarajan, J. Hu, J.-S. Chang, D.-J. Lee, Ethanol production by modified polyvinyl alcohol-immobilized Zymomonas mobilis and in situ membrane distillation under very high gravity condition, Appl. Energy. 202 (2017) 1-5. doi:10.1016/j.apenergy.2017.05.105.

[40] R. Kumar, A.K. Ghosh, P. Pal, Fermentative energy conversion: Renewable carbon source to biofuels (ethanol) using Saccharomyces cerevisiae and downstream purification through solar driven membrane distillation and nanofiltration, Energy Convers. Manag. 150 (2017) 545-557. doi:10.1016/j.enconman.2017.08.054.

[41] I. Hitsov, K.D. Sitter, C. Dotremont, I. Nopens, Economic modelling and model-based process optimization of membrane distillation, Desalination. 436 (2018) 125-143. doi:10.1016/j.desal.2018.01.038.

[42] A. Criscuoli, J. Zhong, A. Figoli, M.C. Carnevale, R. Huang, E. Drioli, Treatment of dye solutions by vacuum membrane distillation, Water Res. 42 (2008) 5031-5037. doi:10.1016/j.watres.2008.09.014.

[43] S. Santoro, I.M. Vidorreta, V. Sebastian, A. Moro, I.M. Coelhoso, C.A.M. Portugal, J.C. Lima, G. Desiderio, G. Lombardo, E. Drioli, R. Mallada, J.G. Crespo, A. Criscuoli, A. Figoli, A non-invasive optical method for mapping temperature polarization in direct contact membrane distillation, J. Membr. Sci. 536 (2017) 156-166. doi:10.1016/j.memsci.2017.05.001. 
[44] J.-Y. Dai, Y.-Q. Sun, Z.-L. Xiu, Separation of bio-based chemicals from fermentation broths by salting-out extraction, Eng. Life Sci. 14 (2014) 108-117. doi:10.1002/elsc.201200210.

[45] S. Xie, S. Zhang, X. Qiu, C. Yi, Y. Hu, F. Li, J. Quan, Sugaring-Out Effects of Sucrose and Glucose on the Liquid-Liquid Equilibria for the (Water + Acetone + 1-Butanol + Ethanol) System, J. Chem. Eng. Data. 60 (2015) 2434-2441. doi:10.1021/acs.jced.5b00302.

[46] S. Xie, W. Song, C. Yi, X. Qiu, Salting-out extraction systems of ethanol and water induced by high-solubility inorganic electrolytes, J. Ind. Eng. Chem. 56 (2017) 145-150. doi:10.1016/j.jiec.2017.07.006.

[47] D.M. Warsinger, J. Swaminathan, E. Guillen-Burrieza, H.A. Arafat, J.H. Lienhard V, Scaling and fouling in membrane distillation for desalination applications: A review, Desalination. 356 (2015) 294-313. doi:10.1016/j.desal.2014.06.031.

[48] P. Loulergue, M. Weckert, B. Reboul, C. Cabassud, W. Uhl, C. Guigui, Mechanisms of action of particles used for fouling mitigation in membrane bioreactors, Water Res. 66 (2014) 40-52. doi:10.1016/j.watres.2014.07.035.

[49] P. Loulergue, B. Teychene, M. Weckert, C. Cabassud, C. Guigui, Advanced tools for fluid and fouling layer characterization applied to the description of membrane fouling phenomena for particle-organic matter mixtures, Can. J. Chem. Eng. 93 (2015) 249-260. doi:10.1002/cjce.22117.

[50] M. Rezaei, D.M. Warsinger, J.H. Lienhard V, M.C. Duke, T. Matsuura, W.M. Samhaber, Wetting phenomena in membrane distillation: Mechanisms, reversal, and prevention, Water Res. 139 (2018) 329-352. doi:10.1016/j.watres.2018.03.058.

[51] I.L. Borisov, A. Kujawska, K. Knozowska, V.V. Volkov, W. Kujawski, Influence of feed flow rate, temperature and feed concentration on concentration polarization effects during separation of water-methyl acetate solutions with high permeable hydrophobic pervaporation PDMS membrane, J. Membr. Sci. 564 (2018) 1-9. doi:10.1016/j.memsci.2018.07.001.

[52] B. Teychene, C. Guigui, C. Cabassud, G. Amy, Toward a better identification of foulant species in MBR processes, Desalination. 231 (2008) 27-34. doi:10.1016/j.desal.2007.12.006. 


\section{Highlights:}

- Bioethanol production using macro-algal hydrolysate

- Air-Gap Membrane Distillation for ethanol extraction from fermentation broths

- Simultaneous maximization of permeate flux and ethanol enrichment coefficient

- No membrane wetting despite a thick cohesive organic cake on the membrane surface 